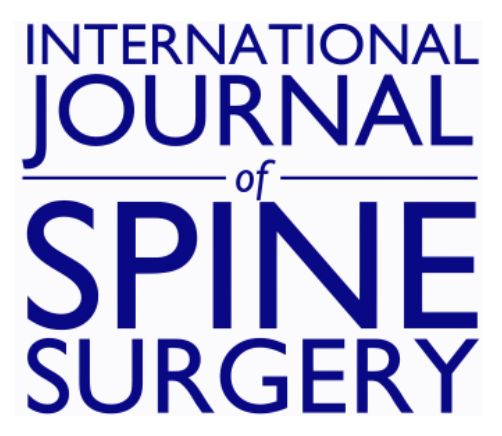

\title{
The Impact of Single-Level Anterior Cervical Discectomy and Fusion on Cervical Sagittal Parameters and Its Correlation With Pain and Functional Outcome of Patients With Neck Pain
}

Mohsen Rostami, Navid Moghadam, Ibrahim Obeid, Morteza Faghih Jouibari, Mohammad Zarei, Mersad Moosavi, Alireza Khoshnevisan, Farzin Farahbakhsh, Fatemeh Moosaie, Saeid Ehteshami, Alireza Borghei, Milad Shafizadeh, Ramin Kordi and Masoud Khadivi

Int J Spine Surg 2021, 15 (5) 899-905

doi: https://doi.org/10.14444/8115

http://ijssurgery.com/content/15/5/899

This information is current as of April 26, 2023.

Email Alerts Receive free email-alerts when new articles cite this article. Sign up at: http://ijssurgery.com/alerts 


\title{
The Impact of Single-Level Anterior Cervical Discectomy and Fusion on Cervical Sagittal Parameters and Its Correlation With Pain and Functional Outcome of Patients With Neck Pain
}

\author{
MOHSEN ROSTAMI, MD, PHD,${ }^{1,2,3}$ NAVID MOGHADAM, MD, MPH, ${ }^{1,3}$ IBRAHIM OBEID, $\mathrm{MD}^{4}{ }^{4}$ \\ MORTEZA FAGHIH JOUIBARI, MD ${ }^{2}$ MOHAMMAD ZAREI, MD ${ }^{5}$ MERSAD MOOSAVI, MD, ${ }^{3}$ \\ ALIREZA KHOSHNEVISAN, MD ${ }^{2}$ FARZIN FARAHBAKHSH, MD, MPH, ${ }^{1,2}$ FATEMEH MOOSAIE, MD ${ }^{1}$ \\ SAEID EHTESHAMI, MD ${ }^{6}$ ALIREZA BORGHEI, MD ${ }^{7}$ MILAD SHAFIZADEH, MD, ${ }^{2}$ RAMIN KORDI, MD, \\ MSC, PHD ${ }^{1}$ MASOUD KHADIVI, MD $^{3}$ \\ ${ }^{I}$ Sports Medicine Research Center, Neuroscience Institute, Tehran University of Medical Sciences, Tehran, Iran, ${ }^{2}$ Department of Neurosurgery, Shariati Hospital, \\ Tehran University of Medical Sciences, Tehran, Iran, ${ }^{3}$ Spine Center of Excellence, Yas Hospital, Tehran University of Medical Sciences, Tehran, Iran, \\ ${ }^{4}$ Orthopedic Spinal Surgery Unit 1, Pellegrin Hospital, Bordeaux Cedex, France, ${ }_{5}^{5}$ Department of Orthopedics, Imam Hospital, Tehran University of Medical \\ Sciences, Tehran, Iran, ${ }^{6}$ Orthopedic Research Center, Mazandaran University of Medical Sciences, Sari, Iran, ${ }^{7}$ Department of Neurosurgery, Rush University \\ Medical Center, Chicago, Illinois
}

\begin{abstract}
Background: This study examines the changes in segmental and global cervical sagittal parameters after singlelevel anterior cervical discectomy and fusion (ACDF) in patients with cervical radiculopathy or myelopathy. We also investigate whether these changes have any relation with postoperative pain and functional outcome of the patients.

Methods: Sixty patients ( 37 females and 23 males) with a mean age of $45.9 \pm 9.5$ years who were candidates of single-level ACDF due to cervical myelopathy or radiculopathy participated in the study. At baseline, 1 month, and 6 months after ACDF, outcomes of the study including sagittal balance parameters, pain intensity, and Neck Disability Index (NDI) were measured among the patients. Intensity of pain and neck disability were measured using the visual analog scale (VAS) and validated version of NDI, respectively. Using a standard lateral cervical radiography, the Cobb angle for occiput-C2, $\mathrm{C} 1-\mathrm{C} 2$, and $\mathrm{C} 2-\mathrm{C} 7$ as well as operation-level angle (OA; Cobb's angle at the level of discopathy), the thoracic inlet angle, and $\mathrm{C} 7$ and $\mathrm{T} 1$ slope angles were measured.

Results: The intensity of pain and neck disability of patients improved significantly during the follow up of the study comparing with baseline measurements $(P<.001)$. There was a significant correlation between the increase of $\mathrm{C} 2-$ $\mathrm{C} 7$ angle, $\mathrm{C} 1-\mathrm{C} 2$ angle, and $\mathrm{OA}$ and improvement in neck pain and NDI at 1- and 6-month follow ups.

Conclusions: We found that changes at $\mathrm{C} 2-\mathrm{C} 7$ angle, $\mathrm{C} 1-\mathrm{C} 2$ angle, and $\mathrm{OA}$ have positive significant correlation with clinical outcome including pain improvement and decrease of disability in patients who undergo ACDF.

Level of Evidence: 3.

Clinical Relevance: The results of this study might be beneficial in selection of cervical cages with appropriate size during ACDF surgery, as our findinds showed that larger cages could lead to better functional outcome in patients.
\end{abstract}

Cervical Spine

Keywords: Cervical Discectomy, Sagittal balance, Disability, radiculopathy, Myelopathy

\section{INTRODUCTION}

Anterior cervical discectomy and fusion (ACDF) is the most common surgical procedure used for the treatment of patients with symptomatic cervical spondylosis and/or radiculopathy. There is growing evidence that sagittal parameters play a key role in determining the appropriate surgical approach in patients who undergo cervical surgery. ${ }^{1-3}$ Biomechanical studies have shown the effect of ACDF on sagittal kyphosis and altered dynamics at levels adjacent to a cervical fusion. ${ }^{4,5}$ However, less interest is paid to the impact of single-level ACDF on the segmental and global cervical sagittal balance parameters and its relationship with functional outcome of the patients.

It was previously shown ${ }^{1}$ that sagittal malalignment of the cervical spine, as measured by $\mathrm{C} 2-\mathrm{C} 7$ sagittal vertical angle (SVA) is related to unfavorable functional and health-related quality of life 
outcomes. This poor outcome might be due to compensatory changes required to keep horizontal gaze and normal posture in patients with sagittal imbalance. In addition, authors ${ }^{6}$ demonstrated that single-level ACDF in patients with cervical myelopathy leads to increased upper cervical lordosis angle (C1-C2) with no significant effect on lower cervical lordosis (C2-C7). While others ${ }^{7}$ found that both global and segmental sagittal balance parameters improve significantly, after one- or multiple-level ACDF.

In this prospective study, we aimed to record the changes in segmental and global cervical sagittal parameters after single-level ACDF in patients with cervical radiculopathy or myelopathy and investigate whether these changes have any relation with postoperative pain (measured by visual analog scale [VAS]) and functional outcome (measured by Neck Disability Index [NDI]) of the patients. The findings of this study could help boost the efficiency of this procedure to get better functionality and quality of life in patients who undergo ACDF.

\section{METHODS}

\section{Participants and Interventions}

Included subjects were older than 18 years with no prior spinal surgery and no clinical spinal deformity with neck pain and/or radicular pain due to single-level discopathy at the level of C4-C5, C5-C6, or C6-C7. Patients' symptoms were resistant to conservative management, and all of them had a magnetic resonance imaging scan indicative of neural compression. The exclusion criteria were having a history of trauma and fracture in the spine; fibromyalgia and depression; inflammatory and neoplastic diseases; immune or metabolic diseases; any disease requiring chronic use of analgesics and nonsteroidal anti-inflammatory drugs; osteoporosis or diabetes mellitus; obesity (body mass index > 30); history of spinal surgery, pregnancy, upper motor neuron disease, or any other neuromuscular disorder; history of connective tissue disease; and complications of surgery (eg, infection at the site of surgery, cerebrospinal fluid leak). The process and aim of the study were described to the patients. All enrolled patients signed written informed consent. The study protocol was approved by the ethical committee of university.

The subjects underwent ACDF through rightsided approach and by a single surgeon. ${ }^{8}$ Anterior

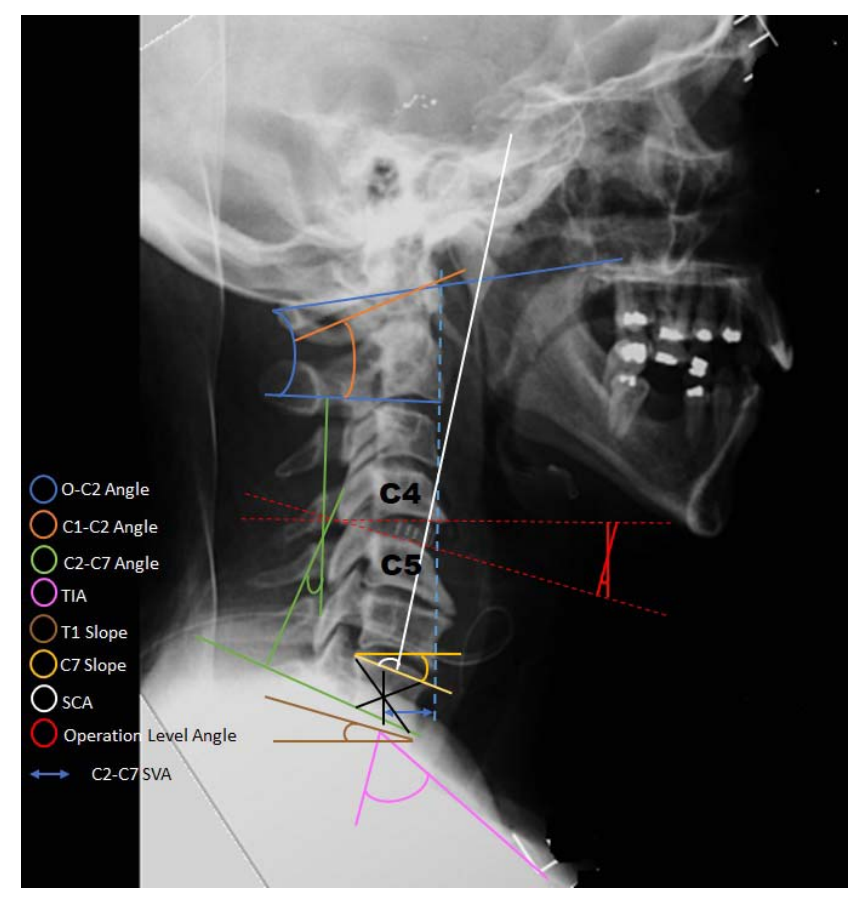

Figure 1. Measured variables of the study in the lateral cervical $x$ ray of a patient after C4-C5 anterior cervical discectomy and fusion.

cervical discectomy and fusion surgery was carried out under a microscopic guide using an interbody cage (Zimmer, Inc, Warsaw, IN) and allograft. No anterior plate was fixed for the patients. The patients received acetaminophen $500 \mathrm{mg}$ as needed and ranitidine $150 \mathrm{mg}$ b.i.d. for 7 days after surgery. Also, ondansetron was prescribed in case of nausea or vomiting in the first 24 hours after surgery. No analgesic drug was administered after day 7 . The patients were discharged on the second postoperative day and were referred to our clinic 1 week later for wound care. Outcome measurements were done before surgery and 1 month and 6 months after surgery.

\section{Outcomes}

Preoperatively and 1 month and 6 months after surgery, all patients underwent lateral cervical spine $\mathrm{x}$-ray study, and the cervical sagittal parameters of the subjects including $\mathrm{C} 2-\mathrm{C} 7$ angle, thoracic inlet angle, T1 slope, C7 slope, $\mathrm{C} 1-\mathrm{C} 2$ angle, craniosellar angle, occiput- $\mathrm{C} 2$ angle, and operation-level angle (OA; Cobb's angle at the level of discopathy), as well as C2-C7 SVA were measured (Figure 1). Lateral cervical radiographs were done in the clavicle position, which was previously described by Horton et al. ${ }^{9}$ The definition of each sagittal parameter was done according to previous publications. ${ }^{10}$ One 
Table 1. Descriptive characteristics of the participants of the study.

\begin{tabular}{lc}
\hline Variable & Value \\
\hline Age, mean $\pm \mathrm{SD}, \mathrm{y}$ & $45.9 \pm 9.5$ \\
Female/male & $37 / 23$ \\
Height, mean $\pm \mathrm{SD}, \mathrm{cm}$ & $166.9 \pm 10.0$ \\
Weight, mean $\pm \mathrm{SD}, \mathrm{kg}$ & $74.1 \pm 10.8$ \\
BMI, mean $\pm \mathrm{SD}, \mathrm{kg} / \mathrm{m}^{2}$ & $26.9 \pm 4.1$ \\
NDI before surgery, mean $\pm \mathrm{SD}$ & $52.1 \pm 20.3$ \\
VAS before surgery, mean $\pm \mathrm{SD}$ & $56.2 \pm 15.7$ \\
Radicular/axial pain & $41 / 19$ \\
With/without neurologic deficit & $25 / 35$ \\
Duration of symptoms, mean (range), mo & $4.2(0.5-14)$ \\
\hline
\end{tabular}

Abbreviations: BMI, body mass index; NDI, Neck Disability Index; VAS, visual analog scale.

radiologic technologist performed all $\mathrm{x}$-ray studies, and all subjects were positioned by the same physician at all follow ups. Radiographic measurements were all performed by 1 experienced author using a picture archiving and communication system.

At baseline, 1 month, and 6 months after surgery, the functional status and pain intensity of the subjects were measured using the NDI and VAS, respectively.

\section{Statistical Analysis}

Data analysis was performed with SPSS 16 (SPSS Inc, Chicago, IL). Data normality was assessed using the 1-sample Kolmogorov-Smirnov test. We computed the Pearson product-moment correlation coefficient to assess the relationship between changes in sagittal parameters and improvement in NDI and VAS at 1 month and 6 months after surgery. We also used a scatterplot to summarize the relationship between specific sagittal parameters and outcome measures.

\section{RESULTS}

In total, 70 patients were recruited in this study, but 10 subjects were excluded from the study due to different reasons: 6 patients declined the calls for follow up, and 4 patients did not show up for follow ups. Finally, 60 patients with a mean age of $45.9 \pm$ 9.5 years were enrolled in the study and participated in 1- and 6-month follow ups. The demographic findings of the patients and their baseline measurements are shown in Table 1 . The mean $\pm \mathrm{SD}$ of pain intensity of the patients was significantly decreased during 6-month $(9.2 \pm 4.5)$ and 1-month (16.6 \pm 9.5) follow up of the study comparing with baseline $(56.2 \pm 15.7)$ measurements $(P<.001)$. Also, the mean \pm SD NDI of the patients improved significantly at 6-month $(9.1 \pm 4.1)$ and 1-month (16.8 \pm 8.7) follow-up sessions comparing with preoperative $(52.1 \pm 20.3)$ measurements $(P<.001)$.

\section{Sagittal Balance Parameters and Neck Pain and Disability}

Correlation between sagittal balance parameter changes 1 month and 6 months after surgery in comparison with before surgery and improvement in disability and pain of patients are shown in Tables 2 and 3, respectively. There was a significant correlation between $\mathrm{C} 2-\mathrm{C} 7$ angle increase and improvement in the NDI at 1-month follow up, but this correlation did not last in 6-month follow up. However, the significant correlation between the increase of $\mathrm{C} 1-\mathrm{C} 2$ angle and $\mathrm{OA}$ and improvement in neck pain and NDI were found at 1- and 6-month follow ups. We used scatterplots to show the positive significant relationship between OA changes and improvement of neck pain and NDI at 1- and 6-month follow ups (Figure 2).

\section{DISCUSSION}

In this prospective study, we found that changes at $\mathrm{C} 2-\mathrm{C} 7$ angle, $\mathrm{C} 1-\mathrm{C} 2$ angle, and $\mathrm{OA}$ have positive

Table 2. Correlation of sagittal balance parameter changes and improvement in neck pain and disability of participants after 1 month.

\begin{tabular}{|c|c|c|c|c|}
\hline Parameter & $\begin{array}{l}\text { Before Surgery, } \\
\text { mean } \pm \text { SD }\end{array}$ & $\begin{array}{c}1 \text { mo After Surgery, } \\
\text { mean } \pm \mathrm{SD}\end{array}$ & $\begin{array}{c}\text { Correlation With } \\
\text { VAS Improvement, } \\
r \text { ( } P \text { Value })\end{array}$ & $\begin{array}{c}\text { Correlation With } \\
\text { NDI Improvement, } \\
r \text { ( } P \text { Value })\end{array}$ \\
\hline C2-C7 angle, deg & $22.2 \pm 12.6$ & $23.2 \pm 13.1$ & $0.229(.07)$ & $0.314(<.01)^{\mathrm{a}}$ \\
\hline SVA, mm & $21.2 \pm 15.5$ & $20.1 \pm 15.1$ & $0.044(.74)$ & $0.012(.92)$ \\
\hline TIA, deg & $74.3 \pm 12.2$ & $74.3 \pm 12.9$ & $0.162(.21)$ & $-0.028(.83)$ \\
\hline T1 slope, deg & $27.5 \pm 5.3$ & $27.4 \pm 5.4$ & $0.011(.93)$ & $0.044(.74)$ \\
\hline C7 slope, deg & $25.0 \pm 6.7$ & $25.0 \pm 6.7$ & $-0.168(.20)$ & $-0.002(.99)$ \\
\hline $\mathrm{C} 1-\mathrm{C} 2$ angle, deg & $27.5 \pm 5.2$ & $27.6 \pm 5.3$ & $0.311(.015)^{\mathrm{a}}$ & $0.361(<.01)^{\mathrm{b}}$ \\
\hline CSA angle, deg & $77.8 \pm 10.3$ & $77.5 \pm 10.1$ & $0.043(.74)$ & $0.034(.79)$ \\
\hline $\mathrm{O}-\mathrm{C} 2$ angle, deg & $23.5 \pm 0.8$ & $23.5 \pm 9.9$ & $0.013(.92)$ & $0.037(.77)$ \\
\hline $\mathrm{OA}$, deg & $3.1 \pm 1.6$ & $4.0 \pm 1.9$ & $0.393(<.01)^{\mathrm{b}}$ & $0.377(<.01)^{\mathrm{b}}$ \\
\hline
\end{tabular}

Abbreviations: CSA, craniosellar angle; NDI, Neck Disability Index; OA, operation-level angle; SVA, sagittal vertical angle; VAS, visual analog scale.

${ }^{a}$ Correlation is significant at 0.05 level.

${ }^{\mathrm{b}}$ Correlation is significant at 0.01 level. 
Table 3. Correlation of sagittal balance parameter changes and improvement in neck pain and disability of participants after 6 months.

\begin{tabular}{lccrc}
\hline Parameter & $\begin{array}{c}\text { Before Surgery, } \\
\text { mean } \pm \text { SD }\end{array}$ & $\begin{array}{c}\text { 6 mo After Surgery, } \\
\text { mean } \pm \text { SD }\end{array}$ & $\begin{array}{c}\text { Correlation With } \\
\text { VAS Improvement, } \\
\boldsymbol{r}(\boldsymbol{P} \text { Value })\end{array}$ & $\begin{array}{c}\text { Correlation With } \\
\text { NDI Improvement, } \\
\boldsymbol{r}(\boldsymbol{P} \text { Value })\end{array}$ \\
\hline C2-C7 angle, deg & $22.2 \pm 12.6$ & $22.8 \pm 12.9$ & $0.260(.04)^{\mathrm{a}}$ & $0.327(.01)^{\mathrm{a}}$ \\
SVA, mm & $21.2 \pm 15.5$ & $20.1 \pm 15.8$ & $-0.142(.27)$ & $0.086(.51)$ \\
TIA, deg & $74.3 \pm 12.2$ & $74.5 \pm 13.5$ & $0.051(.70)$ & $0.009(.94)$ \\
T1 slope, deg & $27.5 \pm 5.3$ & $27.5 \pm 5.4$ & $-0.053(.68)$ & $0.030(.82)$ \\
C7 slope, deg & $25.0 \pm 6.7$ & $24.9 \pm 6.7$ & $0.008(.95)$ & $-0.020(.87)$ \\
C1-C2 angle, deg & $27.5 \pm 5.2$ & $27.6 \pm 5.4$ & $0.296(.02)^{\mathrm{a}}$ & $0.307(.01)^{\mathrm{a}}$ \\
CSA angle, deg & $77.8 \pm 10.3$ & $77.4 \pm 10.7$ & $0.174(.18)$ & $0.167(.20)$ \\
O-C2 angle, deg & $23.5 \pm 0.8$ & $23.5 \pm 9.8$ & $0.056(.67)$ & $0.088(.50)$ \\
OA, deg & $3.1 \pm 1.6$ & $3.7 \pm 1.8$ & $0.336(<.01)^{\mathrm{b}}$ & $0.365(<.01)^{\mathrm{b}}$ \\
\hline
\end{tabular}

Abbreviations: CSA, craniosellar angle; NDI, Neck Disability Index; OA, operation-level angle; SVA, sagittal vertical angle; VAS, visual analog scale.

${ }^{\mathrm{a}}$ Correlation is significant at 0.05 level.

${ }^{\mathrm{b} C}$ Correlation is significant at 0.01 level.

significant correlation with the clinical outcome including pain improvement and decrease of disability in patients who undergo ACDF. Overall, there are a few previous studies regarding the effect of lordosis and alteration of sagittal balance after single-level ACDF on clinical outcomes of patients. Our findings are consistent with the study by Villavicencio et al, ${ }^{11}$ who reported improvement of functional outcome in patients with increase of segmental lordosis. Tang et $\mathrm{al}^{1}$ also reported that improvement of cervical lordosis in patients who undergo posterior cervical laminectomy and fusion is related to better clinical outcomes in these patients. In contrast to these reports, Faldini et $\mathrm{al}^{12}$ found no correlation between changes of sagittal parameters and functional outcome scores of patients after single-level ACDF. Spanos et $\mathrm{al}^{13}$ showed that the slight increase of mean cervical lordosis after ACDF was lost after 12-month follow up and had no significant correlation with pain and function of the subjects. Núñez-Pereira et $\mathrm{al}^{14}$ used C7 slope as an index of global sagittal balance in the cervical region and showed that there is no difference between $\mathrm{C} 7$ slope changes and function of patients after ACDF. Also, in a recent study, Lau et $\mathrm{al}^{15}$ reported on a series of patients who underwent from single-level to 3-level ACDF and plate fixation. They found that cervical lordosis, C2-C7 SVA, and T1 slope were not significantly associated with functional outcomes, specifically NDI and VAS scores of the patients. They assumed that normality of the radiologic measurements at baseline and minimal changes to the parameters after surgery were the possible reasons for this finding. Our results cannot be compared with this study due to different selection inclusion criteria and measurement angles.
According to our results (as shown in Tables 2 and 3), the OA showed the strongest positive correlation with clinical outcomes (including pain and functional disability) in patients after singlelevel ACDF. This finding is in parallel with the results of the study by Siasios et al, ${ }^{6}$ who showed that more lordotic segmental angles result in better functional outcome scores at the postoperative period. We assume that a possible explanation for this finding might be the role of ACDF on restoration of segmental slope at the operation level. This finding has been shown in the study by Zhang et $\mathrm{al}^{7}{ }^{7}$ as they found that global lordotic angle, segmental lordotic angle, and $\mathrm{T} 1$ slope were all improved after ACDF procedure and concluded that ACDF could be used to restore cervical sagittal alignment. Also, considering the recent study by Kim et al, ${ }^{16}$ who showed that ACDF can change not only regional but also the global sagittal parameters, the effect of ACDF on other sagittal parameters such as $\mathrm{C} 1-\mathrm{C} 2$ angle (which is responsible for more than half of cervical sagittal balance ${ }^{6,10,17,18}$ ) could be explained. In fact, the interrelation between upper and lower cervical spine is complex. In case of $\mathrm{C} 1-\mathrm{C} 2$ kyphosis, the $\mathrm{C} 2-\mathrm{C} 7$ angle is hyperlordotic as a compensatory mechanism (downward sequential change), and therefore, when the upper kyphosis is corrected, the low cervical spine lordosis decreases. However, in the case of segmental kyphosis at the low cervical spine, the upward sequential change is more complicated, as an increase of the segmental lordosis at C5-C6 or C6-C7 after surgery might lead to a decrease of the adjacent upper lordosis (C2-C5 or $\mathrm{C} 2-\mathrm{C} 6)$, which will lead to an increase of the $\mathrm{C} 1-\mathrm{C} 2$ angle. ${ }^{16}$ As it is shown in previous studies, ${ }^{10,16,19}$ compensatory mechanisms to try to keep horizontal gaze lead to alteration of cervical sagittal alignment in patients 

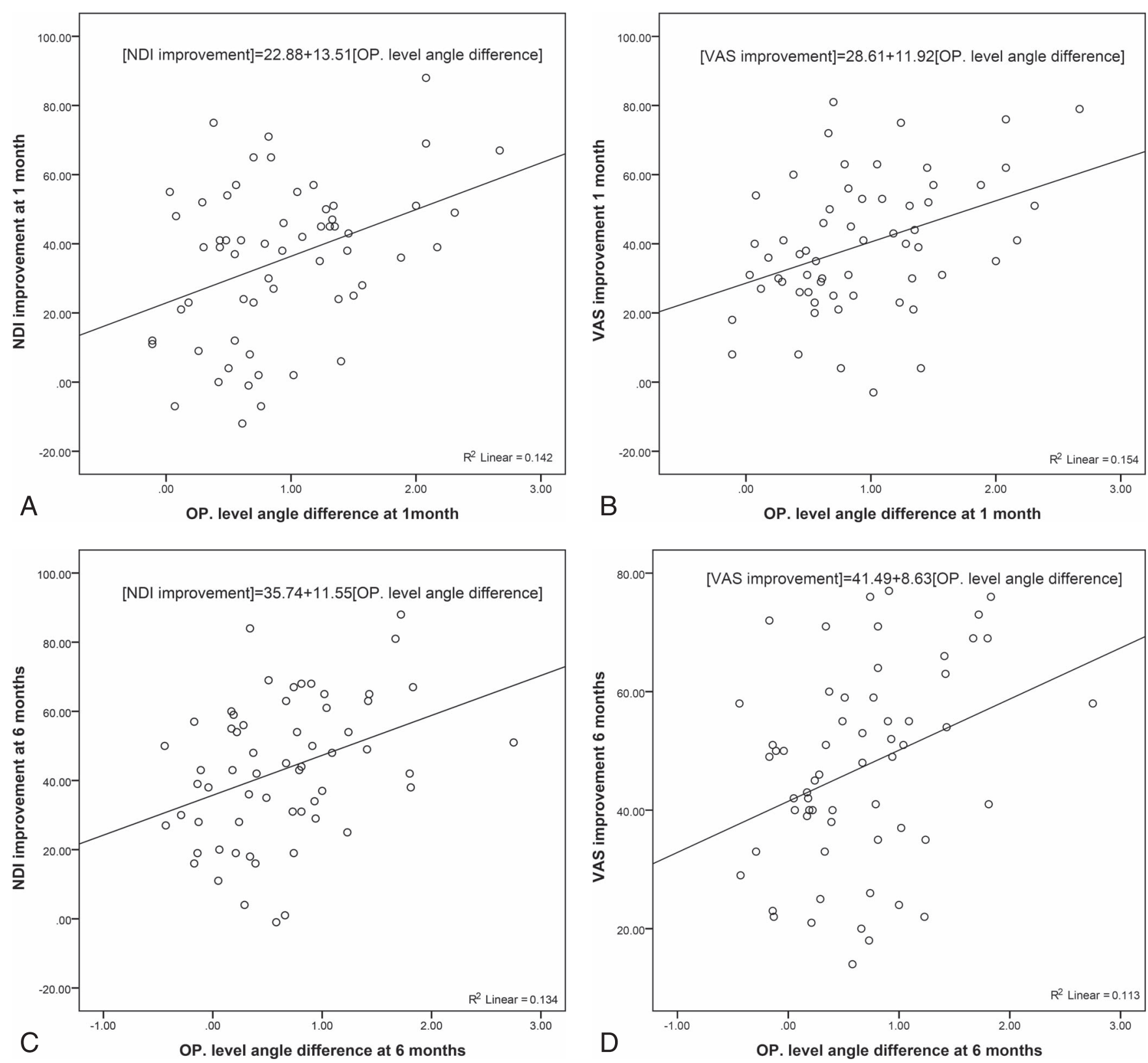

Figure 2. Relation of operation (OP) angle difference at 1 and 6 months and neck pain disability and pain improvement. (A) Relation of OP level angle difference and Neck Disability Index (NDI) improvement at 1 month. (B) Relation of OP level angle difference and visual analog scale (VAS) improvement at 1 month. (C) Relation of OP level angle difference and NDI improvement at 6 months. (D) Relation of OP level angle difference and VAS improvement at 6 months.

with degenerative disc disease. Therefore, restoration of segmental lordosis (as shown by OA) and global cervical lordosis (as shown by increase of $\mathrm{C} 1-$ $\mathrm{C} 2$ and $\mathrm{C} 2-\mathrm{C} 7$ angles) might be considered by every spine surgeon as an indicator to improve the functional outcome of patients.

Faldini et $\mathrm{al}^{12}$ found that cervical lordosis improved 6 months after ACDF but decreased in long-term follow up (after 1 year). Godlewski et $\mathrm{al}^{20}$ showed that, after ACDF, the greatest changes in lordosis and disk space height were noted immediately postsurgery. Baseline values were approximat- ed gradually over time, but the postoperative values at 12 months were still higher than baseline, albeit this change was not correlated with clinical outcomes. In the current study, the patients were followed for only 6 months, and our findings cannot be compared with the Faldini et al ${ }^{12}$ study. The short period of follow up should be considered as one of the limitations of this study. As another limitation, participants were not screened for level of physical activity, which might have a significant role in pain intensity and level of disability of the subjects. ${ }^{21}$ Also, we did not measure all the different 
published angles for the study of the cervical spine sagittal alignment such as the occiput slope, the occiput- $\mathrm{C} 1$ angle, the angle between $\mathrm{C} 2$ and the upper vertebra included in the fusion, and also global sagittal parameters. There is evidence that anatomic change of sagittal balance in the cervical area is associated with compensatory changes in thoracic and even lumbar regions. ${ }^{22,23}$ However, in our study, this reciprocal effect was not identified since only cervical $\mathrm{x}$ rays were taken of the subjects.

\section{CONCLUSIONS}

In this study, we found that single-level ACDF leads to increase of upper and lower cervical lordosis (shown by $\mathrm{C} 1-\mathrm{C} 2$ and $\mathrm{C} 2-\mathrm{C} 7$ angles, respectively). The segmental lordosis at the level of operation (shown by OA) also significantly increased. There was a positive correlation between these parameters and the outcome of patients at 1 and 6 months. It seems that improvement of cervical lordosis has a significant role in improvement of functionality of the subjects. This needs to be further investigated in future studies.

\section{REFERENCES}

1. Tang JA, Scheer JK, Smith JS, et al. The impact of standing regional cervical sagittal alignment on outcomes in posterior cervical fusion surgery. Neurosurgery. 2012;71(3):662669; discussion 669.

2. Bapat MR, Chaudhary K, Sharma A, Laheri V. Surgical approach to cervical spondylotic myelopathy on the basis of radiological patterns of compression: prospective analysis of 129 cases. Eur Spine J. 2008;17(12):1651-1663.

3. Fehlings MG, Gray R. Importance of sagittal balance in determining the outcome of anterior versus posterior surgery for cervical spondylotic myelopathy. J Neurosurg Spine. 2009;11(5):518-519; discussion 519-520.

4. Eck JC, Humphreys SC, Lim TH, et al. Biomechanical study on the effect of cervical spine fusion on adjacent-level intradiscal pressure and segmental motion. Spine (Phila $\mathrm{Pa}$ 1976). 2002;27(22):2431-2434.

5. Hilibrand AS, Carlson GD, Palumbo MA, Jones PK, Bohlman HH. Radiculopathy and myelopathy at segments adjacent to the site of a previous anterior cervical arthrodesis. $J$ Bone Joint Surg Am. 1999;81(4):519-528.

6. Siasios I, Winograd E, Khan A, Vakharia K, Dimopoulos VG, Pollina J. Cervical sagittal balance parameters after singlelevel anterior cervical discectomy and fusion: correlations with clinical and functional outcomes. J Craniovertebr Junction Spine. 2018;9(1):56-62.

7. Zhang Y, Liu H, Yang H, Pi B. Relationship between sagittal balance and axial symptoms in patients with cervical spondylotic myelopathy treated with anterior cervical discectomy and fusion. J Invest Surg. 2020;33(5):404-411.

8. Aronson N, Filtzer DL, Bagan M. Anterior cervical fusion by the Smith-Robinson approach. $J$ Neurosurg. 1968;29(4):396-404.

9. Horton WC, Brown CW, Bridwell KH, Glassman SD, Suk SI, Cha CW. Is there an optimal patient stance for obtaining a lateral 36" radiograph? A critical comparison of three techniques. Spine (Phila Pa 1976). 2005;30(4):427-433.

10. Jouibari MF, Le Huec JC, Ranjbar Hameghavandi MH, et al. Comparison of cervical sagittal parameters among patients with neck pain and healthy controls: a comparative cross-sectional study. Eur Spine J. 2019;28(10):2319-2324.

11. Villavicencio AT, Babuska JM, Ashton A, et al. Prospective, randomized, double-blind clinical study evaluating the correlation of clinical outcomes and cervical sagittal alignment. Neurosurgery. 2011;68(5):1309-1316; discussion 1316.

12. Faldini C, Chehrassan M, Miscione MT, et al. Singlelevel anterior cervical discectomy and interbody fusion using PEEK anatomical cervical cage and allograft bone. J Orthop Traumatol. 2011;12(4):201-205.

13. Spanos SL, Siasios ID, Dimopoulos VG, et al. Correlation of clinical and radiological outcome after anterior cervical discectomy and fusion with a polyetheretherketone cage. J Clin Med Res. 2018;10(3):268-276.

14. Nunez-Pereira S, Hitzl W, Bullmann V, Meier O, Koller H. Sagittal balance of the cervical spine: an analysis of occipitocervical and spinopelvic interdependence, with C-7 slope as a marker of cervical and spinopelvic alignment. $J$ Neurosurg Spine. 2015;23(1):16-23.

15. Lau D, DiGiorgio AM, Chan AK, et al. Applicability of cervical sagittal vertical axis, cervical lordosis, and T1 slope on pain and disability outcomes after anterior cervical discectomy and fusion in patients without deformity. J Neurosurg Spine. 2019;32(1):23-30.

16. Kim JT, Lee HJ, Choi DY, Shin MH, Hong JT. Sequential alignment change of the cervical spine after anterior cervical discectomy and fusion in the lower cervical spine. Eur Spine J. 2016;25(7):2223-2232.

17. Hardacker JW, Shuford RF, Capicotto PN, Pryor PW. Radiographic standing cervical segmental alignment in adult volunteers without neck symptoms. Spine (Phila Pa 1976). 1997;22(13):1472-1480; discussion 1480.

18. Scheer JK, Tang JA, Smith JS, et al. Cervical spine alignment, sagittal deformity, and clinical implications: a review. J Neurosurg Spine. 2013;19(2):141-159.

19. Miyazaki M, Hymanson HJ, Morishita Y, et al. Kinematic analysis of the relationship between sagittal alignment and disc degeneration in the cervical spine. Spine (Phila Pa 1976). 2008;33(23):E870-E876.

20. Godlewski B, Stachura MK, Czepko RA, Banach M, Czepko R. Analysis of changes in cervical spinal curvature and intervertebral disk space height following ACDF surgery in a group of 100 patients followed up for 12 months. J Clin Neurosci. 2018;52:92-99.

21. Noormohammadpour P, Mansournia MA, Koohpayehzadeh J, et al. Prevalence of chronic neck pain, low back pain, and knee pain and their related factors in community-dwelling adults in Iran: a population-based national study. Clin J Pain. 2017;33(2):181-187.

22. Barrey C, Roussouly P, Le Huec J-C, D’Acunzi G, Perrin G. Compensatory mechanisms contributing to keep the sagittal balance of the spine. Eur Spine J. 2013;22(Suppl 6):S834-S841. 
23. Canavese F, Turcot K, De Rosa V, de Coulon G, Kaelin A. Cervical spine sagittal alignment variations following posterior spinal fusion and instrumentation for adolescent idiopathic scoliosis. Eur Spine J. 2011;20(7):1141-1148.

Disclosures and COI: There were no conflicts of interest. This work was supported by Tehran University of Medical Sciences.

Corresponding Author: Masoud Khadivi, MD, Spine Center of Excellence, Yas Hospital,
Tehran University of Medical Sciences, North Nejatollahi St, Tehran, Iran. Phone: (+98) 21 42160000; Email: dr.m.khadivi@gmail.com.

Published 3 December 2021

This manuscript is generously published free of charge by ISASS, the International Society for the Advancement of Spine Surgery. Copyright (c) 2021 ISASS. To see more or order reprints or permissions, see http://ijssurgery.com. 